\title{
Contextual Classification at Out On The Shelves Library
}

\author{
Amber Dierking \\ University of British Columbia \\ amber.s.dierking@gmail.com
}

\begin{abstract}
Out On The Shelves is Vancouver's only Lesbian, Gay, Bisexual, Transgender, Two-Spirit, Queer, Intersex, Aromantic/Asexual (LGBT2QIA+) library. Due to recent organizational changes, it has become apparent that its current classification system is no longer working effectively. Not only was the previous system unstructured and confusing, it failed to explicitly represent many aspects of the community it serves. This project was undertaken during the summer of 2018, researching alternative classification and queer issues in knowledge organization to determine how to improve it. This research, combined with careful consideration of the needs of the library itself and its users, suggested that building a local, contextually-situated, classification system would be best. A new classification system has been built for Out On The Shelves Library, and will be implemented in several stages beginning in October 2018, with the end goal to be finished by the end of December 2018. The new system intends to be living and changeable, one that lays bare its structures and decisionmaking processes while centering and celebrating the LGBT2QIA+ community and working within the realities of being a small, unfunded, volunteer-run, public library.
\end{abstract}

\section{Keywords}

LGBT2QIA+, queer libraries, alternative classification

\section{INTRODUCTION}

Out On The Shelves Library states a mission to, "foster a free, accessible, and safe space for LGBT2QIA+ people and their allies to discover and share stories and resources centering on LGBT2QIA+ experiences. We understand that LGBT2QIA+ people stand at the intersection of multiple communities and identities, and we seek to empower and support them by providing access to materials that reflect their realities." (Out On The Shelves, n.d.) However, in the time following the library's move to its new location at the University of British Columbia (UBC) it has become increasingly clear that the current classification system is not fulfilling this mission. In this paper, I will describe the problems inherent in the previous system, several sources and examples I drew from, the process of building the new classification system, as well as its current status and the next steps of the project.

$81^{\text {st }}$ Annual Meeting of the Association for Information Science \& Technology | Vancouver, Canada | Nov. 10 - 14, 2018

Author(s) Retain Copyright

\section{PREVIOUS CLASSIFICATION SYSTEM}

Concerns with the previous system include classification codes that have fallen out of use and the lack of consistent principles of division. There was no explicit hierarchical structure, and mutual exclusivity between classes like "Queer Culture" and "Coming Out" or "International LGBT" and "Lesbian Interest" simply didn't exist. These issues understandably stem from the library's history, built up by community donations over decades and run by volunteers often with no formal education in libraries or knowledge organization. Arranged alphabetically by class for simplicity and discoverability, Out On The Shelves' previous classification system also hindered the collocation of similar topics, therefore missing opportunities to create significant relationships by order of arrangement.

Other aspects of the system reflect harmful and outdated assumptions. By naming separate classes for "Lesbian Interest," "Bisexual Interest," and "Transgender" the previous system implied that gay, cisgender, male interest is the default. Othering identities in this way is starkly contradictory to Out On The Shelves' mission and values. Furthermore, by not naming or creating space for identities and orientations such as Two-Spirit and Asexual, among others, the previous classification system was also complicit in the erasure of these identities.

This project intended to build a system that is more reflective of the mission and values of Out On The Shelves Library. The library's stated values of accessibility, anti-oppression and social justice, Canadian content, decolonization, education, intersectionality, privacy, and own voices content (Out On The Shelves, n.d.) were drafted after the library moved locations and so the previous classification system pre-dates them significantly. Now there is an opportunity to reimagine a classification system while privileging these values.

\section{BACKGROUND RESEARCH}

The many critiques of shortcomings within Library of Congress Classification (LCC) and Subject Headings (LCSH) provided helpful examples of what practices to avoid. Several chapters within Greenblatt's Serving LGBTQ Library and Archives Users in particular showed how recently pejorative terminology was still used and alerted me to the danger of basing my decisions primarily on literary warrant as LCSH does (2010). Drawing also from queer and gender theory, Butler's discussion of language, that categories and abstractions can, "effect a physical and material violence against the bodies they claim to organize 
and interpret," (Butler, 1990, p. 116) inspired deliberation and care in the creation processes. The question, "are userfocused standards likely to be objective?" (Olsen \& Schlegel, 2001, p. 76) as well as Feinberg's discussion of responsible bias (2007), inspired me to discard any pretense of neutrality in favor of a system based on context, one that is equitable rather than equal. Generally, despite there being interest in and acknowledgment of the need for more flexible structures within specialized domains and marginalized communities, the time and funding simply doesn't exist in most cases to create those structures. Because most of these sources, few and far between as they were, discussed correcting subject access within general collections around LGBT2QIA+ terminology and not classification in queer libraries I also sought alternative approaches.

Within North America there are several other small, independent, public libraries centered on queer content and communities that I looked to for context and guidance. The most relevant include Quatrefoil Library in Minneapolis, The Lavender Library, Archives, and Cultural Exchange (LLACE) in Sacramento and La Bibliothèque à Livres Ouvert in Montreal.

\section{EXECUTING THE PROJECT}

\section{Goals for the New System}

\section{Updated to Reflect Current Language}

Rather than basing the new system exclusively on the current collection as-is, it will be based around the library's mission and values. This approach means that gaps in the collection will be made explicit, hopefully serving as a visual reminder and catalyst of potential growth. A queer solution as it were, "built to highlight and exploit the ruptures in our classification structures" (Drabinski, 2013, p. 96-97).

\section{Logically Ordered and Arranged}

The browsing experience will be enhanced by revealing significant relationships via the ordering of classes and their subcategories, as well as revisiting spine labels (colored stickers) which have not been consistently applied and have not, in their previous iteration, created genuinely new or valuable experiences for library users. Spine labels can create opportunities for subversion within a hierarchical system and increase the visibility of an otherwise dispersed subject - an effect I intend to take full advantage of moving forwards.

A Living System, Responsive to its Context and Community Built-in mechanisms for making changes are especially essential as Out On The Shelves Library primarily serves the LGBT2QIA+ community which is constantly growing and evolving as is the language it uses to describe itself. With a new system built specifically to be used by Out On The Shelves Library and its community, independent of a parent organization, we hope it will be easier to support ongoing modifications.

\section{A Historical Record}

The evolution of this classification system will be recorded to promote transparency. Tracking updates to the schema will help volunteers and community members, now and in the future, understand how and why the system came to be the way it is. Hopefully this record will also empower them to make changes when necessary.

\section{Building a Classification System}

With these goals approved by the Out On The Shelves volunteer team, the next step was to build the actual system. After sketching several preliminary options I picked two perspectives to explore more thoroughly, a subject-based system, and an identity-based system. Both had several major flaws.

First, the subject-based system granted the most flexibility and even distribution in terms of what and how materials could be represented. There was nothing, however, in this perspective that explicitly spoke to and valued LGBT2QIA+ lives and experiences but still plenty that could help perpetuate unwelcome societal norms. Fully embracing this perspective which wouldn't privilege the very essence of the library felt like a failure to engage with the central purpose of this project. The second system was quite the reverse: an identity-based system that took the acronym "LGBT2QIA" as its primary level of division. However, this perspective quickly revealed itself to be equally if not more flawed than the first. Its primary shortcoming was the impossibility of maintaining mutual exclusivity while representing intersectional identities and subjects with any degree of accuracy, which therefore made this system untenable despite its value in centering queerness.

After considering these contradictions a compromise was reached by melding the two systems together. "Identity" became a new class within the subject-based system which had since undergone several revisions making it less unwieldy. This merger, combined with clear, comprehensive class definitions and cataloging instructions has the potential to richly represent the range of materials and subjects in the collection without minimizing the visibility and centrality of LGBT2QIA+ content.

\section{Current Status}

As of August 2018, the classification system has been created and is undergoing final revisions. Way finding devices, an updated volunteer training manual of how to use the new classification system while cataloging materials, and a document to track the history of changes made to the system have also been developed and were completed by the end of August 2018. Implementation of the new classification system will take place over the following academic term. At the time of the ASIS\&T SIG/CR workshop in November 2018 the classification system will be complete and the re-organization and re-cataloging process of the books will be in progress. A second, complementary, project regarding digital subject access at Out On The Shelves is ongoing, and will be addressing many 
of the same concerns as this project from different perspectives.

\section{CONCLUSION}

Given the specific context of Out on the Shelves Library, a new classification system has been created: imperfect, but intended to be as inclusive and transparent as possible while incorporating clear pathways for future modifications. These are essential aspects of the system because, "the categories that designate what library books are about actively produce, reproduce, and privilege certain subjects and disciplinary norms." (Adler, 2017, p. 2). If Out On The Shelves, by virtue of having a classification system, cannot avoid reproducing and privileging certain subjects and norms, it can at least lay bare the structures by which it does so.

\section{REFERENCES}

Adler, M. (2017). Cruising the library: Perversities in the organization of knowledge (First ed.). New York: Fordham University Press.
Butler, J. (1990). Gender trouble: Feminism and the subversion of identity. New York: Routledge.

Drabinski, E. (2013). Queering the catalog: Queer theory and the politics of correction. The Library Quarterly 83(2), 94-111.

Feinberg, M. (2007). Hidden bias to responsible bias: an approach to information systems based on Haraway's situated knowledges. Information Research 12(4).

Greenblatt, E. (2010). Serving LGBTIQ library and archives users: Essays on outreach, service, collections and access. Jefferson, N.C: McFarland \& Co., Publishers.

Olson, H. A., \& Schlegl, R. (2001). Standardization, objectivity, and user focus: A meta-analysis of subject access critiques. Cataloging \& Classification Quarterly $32(2), 61-80$.

Out On The Shelves. (n.d.). Retrieved August 1, 2018, from https://outontheshelveslibrary.com/ 